\title{
Euphemisms as the Means of Inferiority Category Expression in the English Language
}

\author{
Alexander Ptashkin \\ Tomsk Polytechnic University \\ Email: pt.alexandr@gmail.com \\ Dmitry Yakel \\ Tomsk Polytechnic University \\ Email: yakeld@outlook.com
}

Doi:10.5901/mjss.2015.v6n3s2p430

\begin{abstract}
This article deals with the contextual analysis of the language components that express distant periphery of semantic field of inferiority category. The author states that the category of inferiority is the semantic category with complex system of language means. Such system has the core, near periphery and far periphery. The core includes the elements that are fixed in dictionaries, and are the brightest representatives of the category. Near periphery is formed by means of non-standard lexis: colloquialisms, slang words, special slang, and vulgarisms. Far periphery is presented by euphemisms. The category of inferiority is considered as the constituent of deviation category. Inferiority and Deviation are seen as the system "categorysubcategory." Deviation forms the highest level of categorization. Category of inferiority can be the basic level according to traditional scheme of mental unit structuring. The focus of this work is to present lexical units that form distant periphery of inferiority category taking into account versions of American English, British English, and Australian English. The standard classification of euphemisms, slang words, dysphemisms is taken. The author considers the term "semantic category" as an abstract concept that can "gather" mental units of the same meaning class.
\end{abstract}

Keywords: euphemism, category, deviation, inferiority, semantic field, core, periphery

\section{Introduction}

"Euphemism refers to the use of deliberately indirect, conventionally imprecise, or socially "comfortable" ways of referring to taboo. Embarrassing, or unpleasant topics. Although many euphemisms are self-evident, as in formulas like "four-letter word" or "go to the bathroom," a surprisingly large number are unconscious and collective. Euphemism is a continuous process, since it is an essential mode of politeness, although there are periods, such as the Puritan and Victorian eras, when it is more pronounced and evident. $<\ldots>$ In origin euphemism is profoundly involved with word magic, a primitive but enduring superstition that there is a mystical relationship between words and things. The etymology of the word in the Greek roots eu ("well") and pheme ("to speak") is revealing, since the process is to describe the situation as better than it is, or to avoid a taboo topic, thereby pacifying some dreaded force by not offending it" (Hughes, 2006).

"Euphemism is a genuine collective attempt to avoid an embarrassing topic that often becomes undermined by association, whereas pseudo-euphemism typically betrays certain elements of humorous connivance and irony. Thus to say "Snooks is a bit slow on the uptake" is a euphemism, whereas to say "Snooks is two cards short of a full house" is a pseudo-euphemism. Pseudo-euphemism draws attention to itself by being maliciously clever: thus "slow on the uptake" is an established phrase, a variation of "slow-witted," whereas "two cards short of a full house" is a creative variation of a fertile new idiom discussed" (Hughes, 2011).

"Moreover, euphemisms are closely related to slang at first glance, given that both are colloquialisms, but the difference is that they seek to restate or deflect a harsh, perhaps too-realistic term or phrase. $<\ldots>$ Both slang and euphemisms can be geographic- and occupation-based as well" (Bopp, 2011).

Informal words are considered as a good source of constructing the semantic field of inferiority category in the English language. Their main peculiarity is the presence in social life. What is more, they are meant to be the mirror of a certain culture, its condition and stereotype.

The task of this work is to present the lexical units that form the levels of semantic construction within the notional unit inferiority. 


\section{Research Methodology}

These lexical units are the "members" of inferiority category in the English language. The category of inferiority in the English language is presented by the traditional structure of the semantic field. The key point of this structure is that the category of inferiority is the part of deviation category in English. They function together in relations "category (deviation)subcategory (inferiority). These categories can function independently (Ptashkin, 2013a; Ptashkin, 2013b). As the subcategory, inferiority stands as the basic level of deviation category, in such structure deviation is seen as the highest level of categorization. Third level of deviation category is the sphere where concrete representatives of the category are shown. For instance, deviation - inferiority - Alzheimer's disease, etc.

This system of inferiority category within deviation includes the core expressed by the words that are bright representatives of the mental unit. The core of the semantic field of inferiority is formed by means of three components 1) medical names of different mental disorders and pathologies of mind; 2) lexical units of neutral-bookish style, expressing defective development of mental abilities; 3) lexical units o neutral-bookish style, representing different psychic disorders.

Near periphery is represented by words of informal style, while far periphery is formed by means of phrases of appraisive type, they have the function of euphemisms: not all there, a brick short of a load, off one's rocker, off one's head, round the bend, off one's trolley, round the twist, not the full shilling, a sandwich short of a picnic, sick in the head, etc. (N. Amer.) a brick shy of a load, full of locoweed, off the wall, etc. (Soanes, 2001). Euphemisms with the marker "low intelligence" are formed in the following list: academically subnormal, airhead, backward, card short of a full deck, cerebrally challenged, Charlie uncle, cupcake, developmentally challenged, differently abled, disparate impact, dope, double dutch, dummy, Dutchman, Dutchy, educable, elevator does not go to the top, floor (the), fifty cards in the pack, fogbound, have a slate loose, intellectually challenged, jerk, jerk-off, learning difficulties (with), light in the head, meathead, mentally challenged, minus, minus buttons, minus screws, muggy, natural, not all there, not sixteen annas to, the rupee, not sixteen ounces to the pound, penny short of a pound, people with learning difficulties, play with a full deck, pointy head, retard, right Charlie, simple, slate-off, slow, slow upstairs, soft, thick, thick in the head, tinhead, uniquely proficient, up top, want, want some pence in a shilling, wanting, without the highest IQ. in the world (Holder, 2002). In Australian English these expressions can be met to describe someone appears stupid or who displays low intelligence: a book short of a library, a can short of a slab, an egg short of a dozen, a grape short of a bunch, a snag short of a barbie, a stubby short of a six pack (Australian Phrasebook, 1998).

For instance, according to data from "British National Corpus" (BNC):

Obviously they couldn't be ridden on a mountain, but magazine articles and newspaper features began treating them as a status symbol, and so every airhead on a salary of over $£ 20,000$ a year rushed out to buy one and take it up a mountain (BNC: AS3 1316).

In the focus of this example the lexeme airhead is represented by the meaning "crazy person".

August I will not accept a team of gangsters directed by a mental retard (BNC: AAW 165).

The set phrase mental retard is given in direct meaning "mentally disordered".

It is as if Ted Hughes were himself the patient, suffering maybe from impotence or castration fears, and was here attempting an autotherapy with Shakespeare as a dummy (BNC: AJV 982).

The lexeme dummy represents the semantic field of inferiority category, and have the meaning "stupid".

He and Vivienne were also probably fed up with the teds' meathead mentality (BNC: A6E 595).

Within this context the set phrase meathead mentality includes the meaning considered in the privious example.

Have I remembered to do that? Sometimes kindly people try so hard to get their message across that one would think that they were talking to a mentally backward five-year-old! (BNC: C9R 2865).

The text shows the set phrase mentally backward with the meaning "a person with developmental disorder in mentality."

Susan turned her heroine over, and looked into the painted face of a dummy (BNC: GVL 2169). 
I didn't mean that you half-witted dope! (BNC: EFJ 2467).

The phrase half-witted dope represents the low level of inferiority category, and stands as the element of distant periphery.

The lexemes considered in the following examples are very functional, they are widely used in active vocabulary of usual speaker.

"Corpus of Contemporary American English" includes the following examples of the distant periphery of semantic field of inferiority category within deviation category:

He intends that power to be supplied by Werner, an Indianapolis reporter who earned a 1998 Edward R. Murrow Award for an investigative series on abuse at a home for the developmentally challenged (McDaniel, 1998).

The phrase developmentally challenged is used to denote "a person with disorder of mental character."

You know, it's not exactly for me to judge the cerebrally challenged (Bicycling, 2000).

The phrase cerebrally challenged stands as the synonym of the phrase developmentally challenged.

People are always calling me a meathead, a dummy, telling me I'm too stupid to be a real player, " Parros said (Jenkins, 2007).

The semantic field of inferiority category includes the lexemes that function as euphemisms - meathead, dummy.

Some people thought Amy was a charming airhead. Initially, Brian had thought so, too. Then he had realized he was wrong. He would never have fallen in love with an airhead. He said, "You aren't seriously telling me that Seeing Eye dogs can drive. " "The dog doesn't drive, silly. (Koontz, 2007).

The lexemes airhead and silly are used in neutral style here. They do not indicate the person who is developmentally challenged, but a character who is considered as a stupid girl.

As a result of contextual analysis of the English texts new lexemes with the meaning of "low intellect" were marked in our research as the essential units of the above-mentioned semantic field:

One day, after receiving yet another indifferent response from a potential employer, Pimentel expressed his frustration to one of his differently abled friend, wondering aloud how he could change the way the American public perceived differently abled people (Cleveland. Disunity in Christ: Uncovering the Hidden Forces that keep us Apart).

In this context, the set phrase differently abled is presented by its main meaning: "mentally disordered person". This phrase is the member of distant periphery of inferiotity category.

She said he must have thought she was "a sandwich short of a biscuit." I presume she really meant a "sandwich short of a picnic" (Drum, 2011).

In this example, the set phrase "sandwich short of a picnic" was transformed into "a sandwich short of a biscuit" by a character, the meaning retained unchanged.

He'd been standing next to reserve defensive and Craig Hanneman on the Steeler sidelines during the mother of all mud games in Oakland when Hanneman, looking out at all his rainsoaked Steeler Comrades rolling around in the slop, facemasks full of turf, shouted merrily, "We're all about three bricks shy of a load!" (Hanrahan, 2009).

The character of this passage is impressed by the game, and congratulates his team with winning. The phrase "three bricks shy of a load", following the context, changed its negative meaning into positive one: "lucky men".

The components of inferiority category that are presented as the euphemisms characterize not only the abovementioned mental unit, but also the category of deviation. Thus, the lexemes and phrases of inferiority category function as the components of deviation category. The interconnection of these categories is proved by wide use of lexicon of both structures in one context:

...IQs reported in standard deviation units are the major criteria for determining the level of mental retardation, and each level has its own diagnostic designations (Mercer, 1973).

This approach relies on mathematical measurement and obtained data and uses a range of deviation from the mean to distinguish between normal and abnormal. For example, hypertension, anemia, obesity, or subormal intelligence are conditions that use certain scales and measurements to define normality (Tseng, 2008). 
The nineteenth-century arguments held that while the working class may experience problems as a result of structural factors, and overcome these structural problems through individual agence, the underclass are 'sub-race', born to be deviant or 'subnormal' (Cruickshank, 2003).

\section{Findings and Discussion}

There is an opinion that only neutral of positively coloured phrase can be used in the function of euphemism. The Euphemisms with negative value are expressive, i.e. they are attractive for the speaker, but the negative meaning "cast the shadow" on the speaker (Senichkina, 2006).

It is necessary to point out that high degree of expressiveness is decisive moment in choosing of a definite phrase instead of a certain word or set expression which the speaker considers unsuitable or undesirable, though this phrase can sound rude or inappropriate, transforming into dysphemism (Allan, 2006).

In the following contexts the characters try to avoid the usage of lexemes: insane, lunatic, mad, etc.:

"There was blenderized meat in those jars; that's for sure. But we've learned the professor was two slices of bread short of a sandwich, right? That diet he was creating could have been complete bogus." "May be not. He was a pretty respected scientist, despite his mental health problems (Sweeney, 2010).

Miranda sighed, figuring the old boy was too far round the bend to be of any help (Harrison, 1997).

Most of such phrases are registered in the dictionaries as euphemisms, for instance, a brick short/shy of a load, off one's head, round the bend, round the twist, etc. (Holder, 2002).

According to the analysis of dictionaries and contextual analysis, we come to conclusion that the mental unit Inferiority is closely connected with such concepts as Head, Load, Bend, Twist, Health, Bread, Air, Meat, Brick, Rocker, Trolley, Shilling, Picnic, Wall, Deck, Uncle, Cards, Fog, Minus, Rupee, Pound, Diffuculty, Simplicity, Upstairs, Proficiency, $I Q$, Book, Egg, Grape, Barbie, etc. It means that the category of mental disorders is very productive, and culturally marked. It is necessary to point out that all of these units represent the lowest level of categorization taking into account the classical system of category levels: high, basic, and low. Low level does not mean something being bad. According to such abstraction, the representatives of the lowest level are the most widely used terms; they are more frequent in speech than other components.

\section{Concluding Remarks}

Taking into account the characteristics of deviation category and category of inferiority, we should point out that these two mental units are organized in the form "category-subcategory" (Ptashkin, 2014a). Language means of such system demonstrate the hierarchy, it can be proved by the existence of semantic fields. Core, near periphery and far periphery are distinguished in this structure. One of the main peculiarities of inferiority category is the presence of physical and mental components that is why it is necessary to consider language means of these constituents separately. Both components are presented by lexemes, set phrases (Ptashkin, 2014b). These lexemes were intentionally marked by its dialect usage: North American, Australian, etc. New meanings in the contextual analysis can be considered as the important finding in question of lexical unit functioning in the English language.

Euphemisms give chance to see the peculiarities of distant periphery structuring within categories of deviation and inferiority, analyzing the variants of meanings of lexemes, set phrases, representing various levels of category abstraction. These meanings allow to concretize the semantics of mentioned language units, representing inferiority category.

The connection of inferiority category with other concepts is the material for further analysis. Such link between mental units helps to analyse human mental activity mechanisms at different levels.

\section{References}

Allan, K. (2006). Forbidden Words: Taboo and the Censoring of Language. Cambridge: Cambridge University Press.

Australian Phrasebook (1998). Victoria: Lonely Planet Publications.

Bicycling (2000). Style: Ask the Style Man, Vol. 41, Iss. 10, pp. 102.

Bopp, R. E. (2011) Reference and Information Services: An Introduction. Santa Barbara: ABC-CLIO. 
British National Corpus (BNC) (2014). Retrieved September 19, 2014, from http://www.natcorp.ox.ac.uk/

Cleveland, Ch. (2013). Disunity in Christ: Uncovering the Hidden Forces that Keep Us Apart. Downers Grove, II: InterVarsity Press.

Cruickshank, J. (2003). Critical Realism: the Difference That It Makes. London: Routledge.

Drum, R. (2011). The Simple Life?: A Candid Account of Rosie Drum's Life from 1960s Scotland. Bloomington: Xlibris Corporation.

Hanrahan, Ph. (2009). Life After Favre: A Season of Change With the Green Bay Packers and Their Fans. New York: Skyhorse Publishing.

Harrison, P. (1997). Forbidden Summit. New York: Berkley Books.

Holder, R. W. (2002). Hot Not to Say What You Mean: A Dictionary of Euphemisms. Oxford: Oxford University Press.

Hughes, G. (2006). An Encyclopaedia of Swearing: the Social History of Oaths, Profanity, Foul Language, and Ethnic Slurs in the English-speaking world. New York: M.E. Sharpe.

Hughes, G. (2011). Political Correctness: a History of Semantics and Culture. New York: Wiley-Blackwell.

Jenkins, L. (2007). Today in the N.H.L., Nothing Rolls Off the Ducks' Backs. New York Times, Section D, Column 1, Sports Desk, Hockey; pp. 1.

Koontz D. (2007). The Darkest Evening of the Year. New York: Bantam Books.

McDaniel M. (1998). Big Four Networks Bank on Serious Reporting for Edge in Contested Houston Market. Houston Chronicle, No. 5, p. 8.

Mercer, J.R. (1973). Labeling the Mentally Retarded: Clinical and Social System Perspectives on Mental Retardation. Los Angeles: University of California Press.

Ptashkin, A. S. (2013a). Concept "Genocide" as the Form of the Legal Regulatory Component in the Deviation Category in the English Language. World Applied Sciences Journal, No. 23(5), pp. 621-627.

Ptashkin, A. S. (2013b). The Concept "Ethnocide" Within the Category of Deviation in the English Language. World Applied Sciences Journal, No. 28(6), pp. 826-828.

Ptashkin, A. (2014a). The Concepts of "Beauty" and "Pathology" within the Biological Component of Deviation Category (in the English Language). Xlinguae: European Scientific Language Journal, No. 7 (1), pp. 21-28.

Ptashkin, A. (2014b). Subcategory of Evolution within Deviation Category in the English Language. Mediterranean Journal of Social Sciences, № 5 (20), pp. 2327-2331.

Senichkina, E. P. (2006). Euphemisms of the Russian Language. Moscow: High School.

Soanes, C. (2001). The Oxford Dictionary, Thesaurus, and Wordpower Guide. Oxford University Press.

Sweeney, L. (2010). The Cat, the Professor and the Poison: A Cats in Trouble Mystery. New York: Penguin Books.

Tseng, W. (2008). Cultural Competence in Health Care. New York: Springer. 